\title{
EXERCÍCIO DO PODER FAMILIAR E A EDUCAÇÃO DA CRIANÇA E ADOLESCENTE: A POSSIBILIDADE DE OPÇÃO PELA EDUCAÇÃO DOMICILIAR NO BRASIL
}

\section{EXERCISE OF PARENT'S AUTHORITY AND THE EDUCATION OF CHILDREN AND TEENAGERS: THE POSSIBILITY OF OPTION FOR HOMESCHOOLING IN BRAZIL}

${ }^{1}$ Antonio Jorge Pereira Júnior
${ }^{2}$ Nardejane Martins Cardoso

\section{RESUMO}

O artigo avalia possibilidade de educação domiciliar no Brasil, como desdobramento do poder-dever de educar dos pais. Aborda-se o sistema de ensino brasileiro, estruturado na educação escolarizada, que ainda não esclarece possibilidade da instrução direta pela família. O trabalho traz os fundamentos para a defesa do ensino familiar e apresenta a discussão judicial. O estudo utiliza-se da pesquisa bibliográfica. Justifica-se diante das ponderações quanto à liberdade e deveres no que é pertinente à educação e formação dos filhos. Concluise que a educação infanto-juvenil é dever da família, sociedade e Estado. Ao permitir-se à educação domiciliar, está-se garantindo liberdade e pluralismo.

Palavras-chave: Poder familiar, Educação domiciliar, Autonomia privada, Família, Criança e adolescente

\begin{abstract}
The article evaluates the possibility of homeschooling in Brazil, as a development of the power and duty to educate parents. It addresses the Brazilian education system, structured in school education, that still does not explain the possibility of homeschooling. The work provides the foundation for the defense of family education and presents the litigation. The study is used bibliographic research. Justified on the weights on freedom and duties that are relevant to education and training of children. Concluded that children's education is duty of family, society and state. By allowing themselves to homeschooling, one is guaranteeing freedom and pluralism.
\end{abstract}

Keywords: Parent's authority, Homeschooling, Private autonomy, Family, Children and teenagers

\footnotetext{
${ }^{1}$ Doutor em Direito pela Universidade de São Paulo - USP, São Paulo, SP, Brasil. Professor da Universidade de Fortaleza, UNIFOR, Ceará, CE. E-mail: antoniojorge2000@gmail.com.

${ }_{2}^{2}$ Mestra em Direito Constitucional pela Universidade de Fortaleza - UNIFOR, Ceará, CE, Brasil. Professora na Faculdade Vale do Jaguaribe, FVJ, Rio Grade do Norte, RN. E-mail: nardejane_martins@ @otmail.com.
} 


\section{INTRODUÇÃO}

A educação é fundamental à sobrevivência da espécie humana. Educar em sentido amplo significa repassar saberes, orientar para formação moral. Também envolve o ensino técnico, religioso, combinado ao aprendizado, que ocorre durante todo o percurso da vida. Os pais são educadores perenes, enquanto os filhos são os destinatários da ação de educar.

A família é a célula base da sociedade. Não apenas por estar disposto no texto constitucional brasileiro, e de outros países do mundo livre. Mas, porque, a família detém funções fulcrais à manutenção da civilização humana. Nesta instituição, o indivíduo tem seus primeiros contatos, inicia sua socialização, começa a compreender a existência do outro, aprende a dividir espaço, tempo, carinho, momentos, com outras pessoas.

Não deveria ser necessário ter que abordar a educação como dever da família, haja vista que no ordenamento jurídico está previsto como dever legal dos pais educar sua prole. Contudo, observa-se que há um distanciamento entre educação e uma de suas formas: a instrução, ou educação formal, ou educação escolarizada. E, mais que isso, preocupa a comunidade jurídica e pedagógica, e, também, aos políticos, o distanciamento entre escolas e famílias.

Enquanto que, antes do século XIX, a família lidava com todo o processo formativo das crianças, atualmente tem-se uma inversão, e deposita-se nas escolas e professores responsabilidades e deveres de formação moral e ética, que vão além da capacidade das instituições de ensino. Haja vista que estas deveriam ater-se à educação formal.

Socializar e garantir que os filhos sejam agentes produtores e, mais que isso, pessoas, indivíduos capazes de gerir suas próprias vidas e participar da coletividade, é dever primordial e primeiro dos pais ou, na falta destes, de quem lhes faça as vezes, sendo responsáveis, presentes no âmbito familiar.

Destarte, questiona-se o motivo de se considerar, implicitamente, que o Estado brasileiro proíba a Educação Domiciliar, mundialmente conhecida como Homeschooling. O escopo do trabalho, portanto, é demonstrar que não há impedimento à modalidade de ensino formal, alternativa ao modelo escolar. Ao contrário, diante do direito de liberdade, e sob a perspectiva de que a família é a instituição mais importante às crianças e adolescentes, é possível instituir a permissão à educação domiciliar, no mínimo. 
Justifica-se isso, pois, se filhos não são considerados como "propriedade", visto que estão sob a tutela e proteção de seus pais, menos ainda criança e adolescente seriam "propriedades" do Estado ou de instituições oficiais de ensino. Por isso, a educação domiciliar não pode ser vista como danosa, nem como meio de afastar menores de dezoito anos do convívio social.

A socialização não advém apenas da escola. Socializar é dever, antes de tudo, da família. Somente diante da falha desta instituição é que sociedade e Estado podem e devem agir, pelo melhor interesse e proteção integral da criança ou adolescente, alvo de negligência ou imprudência daqueles que deveriam cuidar e prover seu desenvolvimento.

A metodologia utilizada para concretização do trabalho é bibliográfica com foco em livros e artigos científicos voltados ao tema de forma direta ou indireta. Analisam-se ainda a legislação voltada à educação e ao direito da criança e adolescente, bem como se observam decisões judiciais dos tribunais superiores brasileiros, que tratam sobre a temática da educação domiciliar.

Por conseguinte, no primeiro tópico do artigo, aborda-se o poder familiar, e seu conceito no Estado brasileiro, e sua relação com o dever de educação. No segundo, analisa-se o sistema de educação brasileiro, disposto na Lei de Diretrizes e Bases. E, no terceiro tópico, trata-se acerca da educação domiciliar, ressaltam-se os julgados existentes sobre a matéria e aborda-se à educação domiciliar que prima pela liberdade e ação da família na tarefa educativa, voltada à formação profissional e cidadã.

\section{O PODER FAMILIAR E OS DEVERES DE CRIAÇÃO E EDUCAÇÃO DOS FILHOS}

O poder familiar pode ser compreendido como "[...] síntese de poderes que possibilitam a condução dos atos da vida da pessoa absoluta ou relativamente incapaz por falta de idade [...] tendo em vista prepará-la para o exercício pleno da liberdade" (PEREIRA JÚNIOR, 2005, p. 150-151).

Esta definição é compatível com os dispositivos legais do Estatuto da Criança e do Adolescente de 1990 e do Código Civil de 2002, que se fundamentam nos artigos 227 e 229 da Constituição Federal de 1988, e abordam o poder familiar inerente aos pais. 
No Código Civil de 2002, o art. 1.630 estabelece a sujeição dos menores de dezoito anos (criança e adolescente) ao poder familiar. Este poder-dever tem os pais como titulares exclusivos, no Brasil (art. 1.631, CC/02), não sendo passível de transferência ou simples desistência. Dentre as atribuições, o inciso I do art. 1.634 do CC/02 estabelece que é dever dos pais dirigir a criação e educação dos filhos.

A atribuição pedagógica dos pais é reforçada no ECA/90, haja vista que o art. 22 afirma incumbir aos pais os deveres de sustento, guarda e educação. Interessa notar ainda o parágrafo único deste dispositivo, no qual se estabelece que é direito dos pais ou responsáveis a transmissão de crenças e culturas, na medida em que possuem a atribuição de educar. Isso não significa autoritarismo, mas uma noção lógica de que a família é o ambiente mais importante para formação da criança e adolescente.

Em 03 de agosto de 2009, a Lei $\mathrm{n}^{\circ}$ 12.010, modificou diversos dispositivos do ECA/90, e ressaltou a importância da convivência familiar, haja vista que a legislação primou pela permanência da criança e adolescente na família natural e de origem, reforçando-se a excepcionalidade da colocação em família substituta, por guarda, tutela ou adoção. A colocação em abrigo seria medida extrema e temporária pois, nesta forma de proteção da criança, haveria ausência da instituição família.

As interferências da sociedade, por intermédio do Conselho Tutelar ou de outro modo, ou do Estado, pelo Ministério Público ou outros agentes responsáveis por direitos e políticas públicas que envolvam a criança e adolescente, devem levar em conta os princípios da cooperação, subsidiariedade, prioridade absoluta e autonomia familiar. É preciso compreender que no contexto dos círculos sociais, a família é o mais próximo e mais adequado para proteção e efetivação dos direitos inerentes aos indivíduos em estágio peculiar de desenvolvimento.

A convivência familiar e a comunitária são fundamentais às crianças e adolescentes, haja vista que são pessoas em período característico de formação, e, portanto, a participação nesse ambiente de sociabilidade permite o desenvolvimento da linguagem, de sua estrutura emocional, racional etc. Assim, importante recordar a lição de Pontes de Miranda sobre a relevância da família para a sociedade, enquanto um dos círculos sociais importantes à continuidade humana:

[...] Tudo isso se passa dentro de sistemas relativamente fechados, que são os círculos sociais, uns envolventes, outros internos, uns que permanecem, outros que passam. A família é círculo interior permanente. Passará também ele? Não sabemos. 


\begin{abstract}
Onde quer que encontremos grupo social, a anomia das relações sexuais e parentais é apenas teórica: praticamente, a família começou com a descendência, e isso quer dizer: antes do homem. As organizações familiares dos animas apresentam formas interessantíssimas, umas simples e outras assaz complexas. Não é de crer-se que a família desapareça. (MIRANDA, 2001, p. 48) (grifou-se).
\end{abstract}

Por conseguinte, torna-se imprescindível ter a dimensão de que o direito à educação, embora fundamental, não surge apenas a partir do Estado. $O$ direito não advém somente do ente estatal. Como explica Pontes de Miranda (2001, p. 53) ao demonstrar a existência dos círculos sociais que inicia com o par homem-mulher, torna-se clã, fatria e tribo, o direito é uma produção destes círculos, estando incluso o Estado, que não é o detentor exclusivo da criação do direito.

[...] A cada círculo social corresponde o seu tipo de direito, o seu sistema. Diante das convicções da ciência, que tanto nos mostram e comprovam explicação extrínseca dos fatos (isto é, dos fatos sociais por fatos sociais, objetivamente), o que se não pode pretender é reduzir o direito a simples produto do Estado. O direito é produto dos círculos sociais, é fórmula da coexistência dentro deles. Qualquer círculo, e não só os políticos, no sentido estrito, tem o direito que lhe corresponde (MIRANDA, 2001, p. 55) (grifou-se).

Por isso, importante notar que as funções da família não podem ser apenas a satisfação individual. Há deveres inerentes a ela que não podem se modificar, ainda que ocorram mudanças socais significantes. Por isso, a família possui funções jurídicas, morais e sociais, e a promoção da educação -inclusive a instrução formal- está das tarefas desta instituição.

Durante o século XX, especialmente a partir dos anos sessenta, fatores levaram à alteração na concepção de família. Fatores de ordem socioeconômica: o aumento de participação do Estado e das organizações privadas na tarefa educativa dos filhos; a desvinculação progressiva do status social do indivíduo em função do casamento; a consolidação e ampliação da força produtiva das empresas, a deslocar para fora do lar o papel econômico que outrora cabia à família, quando era unidade de produção. Restaram à família, basicamente, funções pessoais ou microssociais (PEREIRA JUNIOR, 2012, p. 10-11).

Logo, tem-se que a convivência familiar é anterior à comunitária, desencadeia esta, haja vista que no ambiente familiar há uma maior proteção e atenção ao indivíduo que está desenvolvendo-se física e psicologicamente. A inserção nos ambientes de sociabilidade permite o desenvolvimento das capacidades humanas; por intermédio da educação tem-se o aprimoramento. Por isso, a educação das crianças e adolescentes não pode ser obrigação apenas estatal, mas requer a participação premente da família e da comunidade.

Perante a filosofia social, "a família é uma sociedade natural, primeira e principal entidade responsável pela formação da pessoa humana [...]”(PEREIRA JÚNIOR, 2012, p. 8). 
Logo, compreende-se que, antes da convivência comunitária, existe a familiar, e a socialização do indivíduo começa exatamente na família.

Os artigos 21 e 22 do ECA/90 ${ }^{1}$ traduzem a noção de que poder familiar é compartilhado pelos pais, e que implica no direito de participação na vida da prole, e em contrapartida no dever de orientar, criar, educar e manter os filhos. Esses dois artigos demonstram que os pais não possuem liberdade ilimitada para controle dos filhos, mas que possuem deveres que estão acima e aquém de suas vontades. Ao mesmo tempo, o parágrafo único do artigo 22 do ECA/90 ressalta a liberdade dos pais em transmitir suas crenças e tradições familiares aos filhos.

Ressalta-se ainda, o artigo 33 do ECA/90, que embora trate sobre a guarda, define que os guardiões, que podem não ser os pais, mas atuam em vez destes, têm o dever de prestar assistência educacional. Assim, percebe-se que educar é uma tarefa que atinge não só a família natural e nuclear, mas que concerne também à família ampliada ou mesmo substituta, quando há necessidade de substituir a ausência de poder familiar dos pais.

Diante disso, passa-se ao Capítulo IV, presente no Título II do ECA, que trata dos direitos fundamentais, dentre os quais "o direito à educação, à cultura, ao esporte e ao lazer". $\mathrm{O}$ artigo 53 aduz que toda criança ou adolescente possui direito à educação em vista de seu pleno desenvolvimento e preparo para a vida adulta. $\mathrm{O}$ parágrafo único deste dispositivo ressalta o papel dos pais que possuem o direito de ter acesso e de poder influenciar no processo pedagógico, ou seja, o poder de controle sobre a educação formal e técnica de seus filhos.

Já no artigo 54 do ECA/90 ressalta-se que o Estado tem o dever de assegurar o acesso à educação possibilitando à educação em condições de igualdade e liberdade a todos menores de dezoito anos, nos níveis infantil, fundamental e médio. Além da questão da igualdade, importante ressaltar que o Estado deve possibilitar a escolha, ou seja, a autonomia e a liberdade tanto das crianças e adolescentes, como de suas famílias, na figura dos pais, que detêm o poder familiar.

O artigo 55 do ECA/90 afirma que os pais têm o dever de matricular seus filhos ${ }^{2}$. Eis

\footnotetext{
1،“Art. 21. O poder familiar será exercido, em igualdade de condições, pelo pai e pela mãe, na forma do que dispuser a legislação civil, assegurado a qualquer deles o direito de, em caso de discordância, recorrer à autoridade judiciária competente para a solução da divergência". "Art. 22. Aos pais incumbe o dever de sustento, guarda e educação dos filhos menores, cabendo-lhes ainda, no interesse destes, a obrigação de cumprir e fazer cumprir as determinações judiciais."

2“Art. 55. Os pais ou responsável têm a obrigação de matricular seus filhos ou pupilos na rede regular de ensino".
} 
um dos pontos que requere maior atenção, sendo necessário que sua interpretação se realize de modo sistemático, sob risco de se negar a prioridade dos pais na tarefa que lhes incumbe. A simples "matrícula" em instituição de ensino não substitui e não garante a efetiva educação dos indivíduos, seja ela intelectual, moral, afetiva e social. O comando do dispositivo deve ser percebido como dever de garantia da efetiva formação, inclusive porque nem sempre haverá, efetivamente, a possibilidade real da presença em recinto físico de uma escola. Este artigo, se interpretado como uma obrigação peremptória de frequência escolar, deslegitimaria a possibilidade de Educação Domiciliar, ao mesmo tempo em que, frise-se, não garante a efetiva educação escolar, senão gera uma presunção relativa acerca dela.

\section{O sistema de educação escolarizada no Brasil}

A Lei de Diretrizes e Bases da Educação Nacional de 1996 volta-se especificamente à escolarização. Estabelece, assim, como funciona o sistema escolar, responsável pela educação formal (instrução) no Brasil.

Contudo, não se perde de vista que existem princípios e direitos fundamentais que devem ser respeitados, e não podem ser desconsiderados com vistas à finalidade de efetivar a educação. Isto, pois, o Estado é responsável por garantir o acesso à educação, que não era possível a todos. A universalização da educação é um objetivo de todos os Estados democráticos de direito. Porém, isso não significa que instituições mais antigas e mais importantes que o ente estatal não possuam o mesmo dever de garantir a educação.

A LDBEN/96 regula o sistema educacional brasileiro no que concerne à instrução formal realizada em instituições de ensino. Ainda assim, a legislação ressalta a responsabilidade da família para educar os indivíduos, precipuamente, aqueles que são menores de dezoito anos. A LDBEN/96 estabelece, em parte, os fundamentos da educação nacional, as diretrizes curriculares nacionais para a educação básica e o plano nacional de educação.

O artigo $1^{\circ}$ da LDBEN/96 dispõe a educação como um processo formativo que abrange a convivência familiar, comunitária, laboral, cultural e institucional: "A educação abrange os processos formativos que se desenvolvem na vida familiar, na convivência humana, no trabalho, nas instituições de ensino e pesquisa, nos movimentos sociais e organizações da sociedade civil e nas manifestações culturais” (grifou-se). 
Em seguida, o artigo $2^{\circ}$ da LDBEN propõe que a educação é dever da família e do Estado e pauta-se nos "princípios de liberdade" e ideais de "solidariedade humana", com o fim de desenvolvimento do indivíduo em processo de formação educacional, tanto para cidadania como para o mercado de trabalho. Então, o artigo $3^{\circ}$ da LDBEN estabelece os princípios que o ensino deve guiar-se, e destacam-se, novamente, liberdade e pluralidade:

\begin{abstract}
[...] I - igualdade de condições para o acesso e permanência na escola; II - liberdade de aprender, ensinar, pesquisar e divulgar a cultura, o pensamento, a arte e o saber; III - pluralismo de ideias e de concepções pedagógicas; IV - respeito à liberdade e apreço à tolerância; V - coexistência de instituições públicas e privadas de ensino; VI - gratuidade do ensino público em estabelecimentos oficiais; VII - valorização do profissional da educação escolar; VIII - gestão democrática do ensino público, na forma desta Lei e da legislação dos sistemas de ensino; IX garantia de padrão de qualidade; X - valorização da experiência extra-escolar; XI vinculação entre a educação escolar, o trabalho e as práticas sociais (grifou-se).
\end{abstract}

Nesses primeiros dispositivos da legislação, percebe-se uma preocupação tanto com o direito de igualdade, no sentido de garantir o acesso às instituições de ensino, sejam elas públicas ou privadas, assim como se ressaltam a liberdade e a pluralidade de concepções que devem existir com relação ao ensino no país. O ensino não é apenas público, mas também privado. Isso significa que podem existir os mais diversos colégios, inclusive com ideologias próprias, desde que não vão de encontro à dignidade da pessoa humana ou qualquer dos princípios mínimos que regem os direitos fundamentais.

O Título IV da LDBEN/96 aborda a organização da educação nacional. O artigo $8^{\circ}$ propõe o estabelecimento dos sistemas educacionais em regime de colaboração entre os entes da federação, mas com destaque nas competências administrativas da União, que deve coordenar a Política Nacional de Educação (PNE).

No artigo $9^{\circ}$ da LDBEN/96, por conseguinte, encontram-se as tarefas da União, dentre as quais, destacam-se as seguintes, pois vinculadas diretamente à educação básica: (1) elaboração do PNE; (2) criação e organização de órgãos e instituições do sistema federal de ensino; (3) assistência financeira aos demais entes da federação; (4) estabelecimento de diretrizes para educação básica em conjunto com estados e municípios; (5) garantir a avaliação nacional do rendimento escolar.

No âmbito do Poder Executivo, o Ministério da Educação (MEC) é o órgão do Governo Federal responsável pela educação no Brasil. Dividido em sete secretarias, sendo que a relevante à educação das crianças e adolescentes é a Secretaria de Educação Básica 
(SEB). Esta interessa diretamente ao trabalho, pois tem a responsabilidade de gerir e fiscalizar a educação infantil, fundamental e média (BRASIL, MEC, 2015, online).

Nesse sentido, é importante observar que no sistema previsto na LDBEN/96, a iniciativa privada tem liberdade de criação quanto às instituições de ensino. O artigo 19 da legislação estabelece duas categorias de instituições: as públicas, mantidas e administradas pelo Poder Público; e as privadas, que são criadas e organizadas por pessoas físicas ou jurídicas de direito privado.

Segue assim, o artigo 20 da LDBEN/96 que elenca quatro tipos de instituições privadas: (1) particulares em sentido estrito; (2) comunitárias; (3) confessionais e (4) filantrópicas. A liberdade de criação de instituições de ensino deve respeitar as regras mínimas, que não infrinjam diretamente os fundamentos e objetivos do Estado e sociedade. A pluralidade de concepções de vida não pode ser restrita, principalmente, quando não há danos às pessoas e mitigação dos direitos fundamentais.

Por conseguinte, ao tratar sobre a educação básica no Capítulo II do Título V (Dos Níveis e das Modalidades de Educação e Ensino) da LDBEN/96, os artigos 26 e 27 propõem que os ensinos fundamental e médio devem ter uma base educacional comum. Os parágrafos deste artigo estabelecem os conteúdos mínimos e disciplinas que devem estar presentes em toda a formação dos indivíduos na educação básica. Contudo, essas diretrizes não apontam o método único a ser usado, e nem impedem que outros conhecimentos, doutrinas e teorias sejam ensinados.

O Estado foi criado para ajudar a sociedade na sua manutenção e solução de problemas humanos, mas há que se cuidar para que ele não se torne um todo mais relevante que os indivíduos e a sociedade. Por isso, o Estado não é maior que as pessoas. Elas sim é que compõem a base real e orgânica sobre a qual se ergue o ente abstrato estatal. Assim, é tarefa dos governantes e estatistas proporcionarem resoluções concretas às questões humanas, auxiliar para a construção de uma sociedade livre, justa e solidária, promover a diminuição das discriminações, violências e garantindo a pluralidade de concepções de vida.

A educação é importante e possui uma função de destaque na formação humana, assim está relacionada aos objetivos da República Federativa do Brasil, prevista no artigo $3^{\circ}$ da CF/88 (CURY, 2008, p. 301). Não se pretende negar o escopo de igualdade ao se garantir que a educação fundamental seja um direito público subjetivo. Contudo, é preciso cuidar para 
que a base comum não se transforme num monopólio estatal. Educar não envolve apenas a formação técnica-profissional e cidadã, há que se recordar o papel da família, e a importância da convivência familiar, e, também, a educação moral e cultural.

Embora ressalte que a educação é um direito fundamental e obrigação do Estado, Gina Pompeu (2005, p. 89) ressalta o dever da família com relação à prestação da educação. O dever do Estado não anula o dever/possibilidade de a família ser uma prestadora direta da educação, não apenas moral, mas também formal. A cada direito corresponde um dever, essa relação de correspondência, não significa uma ideia absoluta de que o Estado seja o único capaz de garantir a educação diretamente. Assim, importa lembrar que Estado, família e sociedade possuem o mesmo dever.

O sistema de ensino esboçado pela LDBEN/96 contém uma perspectiva plural e não comporta um monopólio de ação estatal. Concorda-se que é um dever do Estado envidar esforços para promover e possibilitar o acesso à educação por todos os indivíduos, independente de qualquer diferença ou semelhança entre estes, não deve haver discriminação quanto à formação. Todavia, não se pode esquecer que a família também é um agente de promoção desse dever, como previsto no artigo 205, CF/88, e da mesma forma a sociedade (seja por meio dos conselhos de educação ou da criança e adolescente) também tem uma participação relevante.

\section{A POSSIBILIDADE DE OPÇÃO PELA EDUCAÇÃO DOMICILIAR}

A Organização das Nações Unidas (ONU) estabeleceu que a instrução (educação formal) fosse considerada obrigatória e acessível a todos, conforme disposto no artigo XXVI da Declaração Universal dos Direitos Humanos de 10 de dezembro de 1948. Além de expor sobre a acessibilidade e gratuidade do ensino, a ONU preocupou-se com um conteúdo mínimo a pautar a educação, que deve estar voltado à compreensão e tolerância, bem como a importância da responsabilidade dos pais quanto à formação das crianças. Conforme o ponto 3: “[...] Os pais têm prioridade de direito na escolha do gênero de instrução que será ministrada a seus filhos (grifou-se)".

Neste mesmo viés, a Convenção sobre os Direitos das Crianças de 20 de novembro de 1989 (Decreto n 99.710 de 21 de novembro de 1990) em seu artigo 18 afirma que os Estados devem assegurar que os pais cumpram seu dever de educar e proporcionar o desenvolvimento 
dos filhos. Assim, as ações estatais voltam-se para a assistência às famílias e fiscalização para proteção dos menores no contexto familiar. $\mathrm{O}$ documento dispõe que não deve existir restrição à liberdade de criação e direção de instituições de ensino que estejam comprometidas com a tarefa educacional e respeitem a dignidade humana e demais princípios (artigo 28).

Observa-se que as ações estatais para a convenção devem ser no sentido de garantir que todos tenham acesso ao mínimo de educação, considerando, por isso, o ensino primário obrigatório. Do mesmo modo, há uma preocupação com a frequência escolar, no sentido de evitar o esvaziamento das instituições de ensino, um dos locais onde é possível o acesso à educação formal. Por isso, no artigo seguinte tem-se o escopo da educação para as crianças, que relaciona-se ao desenvolvimento individual e socialização, e, vedam-se também restrições à liberdade para criação de instituições de ensino (artigo 29).

No Estado brasileiro, o artigo 227 da Constituição da República Federativa de 1988 (CF/88) afirma que: "É dever da família, da sociedade e do Estado assegurar à criança, ao adolescente e ao jovem, com absoluta prioridade, o direito [...]” (grifou-se). Entre esses direitos está a educação que, conjuntamente à saúde, moradia, alimentação, lazer, trabalho etc, pode ser considerado como o básico para que o indivíduo viva com dignidade.

No que se refere à criança e ao adolescente, agregam-se a convivência familiar e comunitária, constitucionalmente fundamentais ao desenvolvimento desses indivíduos. Assim, compreende-se que as pessoas menores de dezoito anos, que estão em estágio peculiar de desenvolvimento, precisam de constante socialização com a família e comunidade que o cercam, mais do que os adultos, e da mesma forma que os idosos.

A educação formal no Brasil regulamentada refere-se apenas à escolar, como se observou no tópico anterior. Quanto à educação, num sentido amplo, não pairam dúvidas de que o agente precípuo responsável por ela é a família, na figura dos pais ou responsáveis. Ou seja, é um dos deveres advindos do poder familiar. Diante disto, pode-se conceituar a educação domiciliar como o ensino formal provido ou promovido diretamente pelos pais ou responsáveis pelas crianças e adolescentes, como meio alternativo de ensino, em atenção à prioridade absoluta dos direitos fundamentais de crianças, adolescentes ao direito constitucional à educação e à liberdade de ensino, a ao poder familiar, todos eles resguardados na Constituição Federal.

A Associação Nacional de Educação Domiciliar (ANED) afirma que a educação domiciliar não é um método de ensino, não se confunde com a utilização de material didático 
específico, não significa a prática de retirar as crianças e adolescentes da escola, e não se trata de uma ideologia fechada. A educação domiciliar é modalidade de educação na qual os pais do educando são os principais responsáveis e a educação ocorre no contexto da família. $\mathrm{O}$ modo de funcionamento é variado, a depender dos interesses da criança e das escolhas feitas pelos pais e mães (ANED, online).

A educação domiciliar não significa a total ausência do Estado. Não é a completa falta de fiscalização, mas a possibilidade de que, no contexto familiar, seja pelos pais ou responsáveis, seja por professores particulares (preceptores), as crianças e adolescentes possam receber a instrução que receberiam no ambiente institucional. Sem perder de vista a responsabilidade dos pais quanto à educação formal e socialização das crianças. Por isso, o Estado continua presente, mas como um garantidor de que os direitos dos filhos não serão violados pelos pais.

A tese de Édison Prado de Andrade (2014, p. 19) aborda sob a ótica da pedagogia a educação domiciliar, e analisa o movimento social pela educação familiar: "desescolariza-se" a instrução, que passa a ser efetivada diretamente pelos pais. Não se trata de um direito de escolha arbitrário, mas como mecanismo decorrente do poder familiar dos pais, ou mesmo da guarda (art. 33, ECA/90) ou tutela. O autor aponta como funciona o "homeschooling" em outros países e ressalta que o ensino formal de responsabilidade direta da família, quando realizado com acuidade, não implica em danos à socialização ou formação dos infantes. Por isso, deve ser visto como uma alternativa à escolarização.

No mesmo viés, Maria Celi Vasconcelos e João Morgado (2014, p. 208) afirmam que escolarizar não é o mesmo que educar. Os autores ponderam que inserir as crianças e adolescentes em instituições de ensino não é a única forma de garantir a formação científica e o desenvolvimento. Para eles, a socialização não ocorre apenas na escola, apesar de ser uma das consequências. A efetivação da convivência comunitária não depende apenas do Estado, e consiste no esforço conjunto entre os três atores principais no que se refere aos direitos das crianças e adolescentes: família, sociedade e Estado.

Além disso, ao permitir a educação domiciliar, não se pretende acabar com as instituições de ensino ou não fiscalizar se os pais estão realmente cumprindo com seu dever. O sistema escolar é importante e permite o acesso à educação. Contudo, isso não significa que seja o único e melhor meio para formação da criança ou do adolescente. Há que se garantir a igualdade, no sentido de que todos tenham acesso à instrução; porém, não pode ser olvidada a 
liberdade para decidir como concretizar a educação voltada à formação profissional e para a cidadania.

A fiscalização, também, não pode ser uma intromissão desmedida do Estado, mas uma forma de resguardar os interesses das crianças e adolescentes. A interferência do Estado na educação deve guiar-se pelos princípios da cooperação, subsidiariedade, prioridade absoluta, e o respeito à autonomia privada inerente à família, especialmente, ao poder familiar que é exercido pelos pais.

O artigo 208 da CF/88, em seu inciso I dispõe que a educação básica obrigatória gratuita dos 4 (quatro) aos 17 (dezessete) anos é dever do Estado, estando estabelecido que é oacesso à educação básica é um direito público subjetivo ${ }^{3}$. Não restam dúvidas que há um direito prestacional à educação. Que com relação às crianças e adolescentes, no contexto familiar, vincula diretamente os pais. Estes devem agir conjuntamente às instituições de ensino. Haja vista que o artigo 205 da CF/88 também afirma que Estado e família têm o dever de garantir a educação.

Ressaltar o papel da família na educação é perceber sua função como base da sociedade, conforme o artigo 226 da $\mathrm{CF} / 88$, em contraste com o esvaziamento prático da responsabilidade dos pais que delegam, como afirma Fernanda São José (2014, p. 129), cada vez mais a responsabilidade educacional dos seus filhos ao Estado e às escolas.

Esse distanciamento dos pais relativamente à educação escolar ficou evidenciado e gera preocupação no Poder Legislativo, como se pode notar na justificativa para o Projeto de Lei n ${ }^{\circ} 189$ de 01 de junho de 2012, de autoria do Senador Cristovam Buarque, cujo escopo é obrigar que pais e mães comparecessem às reuniões de pais e professores, sob pena de restrições e multas (as mesmas para aquele que deixa de votar nas eleições para cargos do Executivo e Legislativo), a fim de incentivar à participação da família na educação das crianças e adolescentes.

É clarividente que o ideal seria a interação entre família e escola, ofertando às crianças e adolescentes acesso a uma educação informal e formal de extrema qualidade. Entretanto, na prática, o que se vê não é apenas a ausência por parte das famílias no acompanhamento do desenvolvimento destes indivíduos carecedores de um cuidado maior, mas também, a limitação do Estado em proporcionar educação de qualidade e, por conseguinte, com profissionais experientes e bem preparados (SÃO JOSÉ, 2014, p. 141).

A legislação infraconstitucional não aborda a educação domiciliar diretamente. Contudo, estabelece expressamente o dever dos pais que devem garantir a matrícula de seus 
filhos em instituições de ensino. O ECA/90 em seu artigo 55 dispõe que é obrigação dos pais ou responsáveis matricular os filhos na rede regular de ensino. Essa previsão legal adequa-se ao escopo constitucional que é garantir o acesso à educação para todos. São muitos os filhos vinculados à rede oficial de ensino que, infelizmente, estão em situação de abandono intelectual, moral, cultural e social, mesmo quando frequentam as escolas públicas.

No mesmo viés, a LDBEN/96 infere que a educação é dever conjunto da família e do Estado, e ressalta a liberdade e solidariedade humana, com foco no desenvolvimento do educando, no artigo $2^{\circ}$, e, em seguida, no artigo $6^{\circ}$ dispõe que é dever dos pais ou responsáveis efetuar a matrícula no ensino fundamental. Assim como estabelece o seguinte quanto ao ensino fundamental:

Art. $32^{\circ}$. O ensino fundamental, com duração mínima de oito anos, obrigatório e gratuito na escola pública, terá por objetivo a formação básica do cidadão, mediante: I - o desenvolvimento da capacidade de aprender, tendo como meios básicos o pleno domínio da leitura, da escrita e do cálculo; II - a compreensão do ambiente natural e social, do sistema político, da tecnologia, das artes e dos valores em que se fundamenta a sociedade; III - o desenvolvimento da capacidade de aprendizagem, tendo em vista a aquisição de conhecimentos e habilidades e a formação de atitudes e valores; IV - o fortalecimento dos vínculos de família, dos laços de solidariedade humana e de tolerância recíproca em que se assenta a vida social. $\S 1^{\circ}$. É facultado aos sistemas de ensino desdobrar o ensino fundamental em ciclos. $\S 2^{\circ}$. Os estabelecimentos que utilizam progressão regular por série podem adotar no ensino fundamental o regime de progressão continuada, sem prejuízo da avaliação do processo de ensino-aprendizagem, observadas as normas do respectivo sistema de ensino. $\S 3^{\circ}$. O ensino fundamental regular será ministrado em língua portuguesa, assegurada às comunidades indígenas a utilização de suas línguas maternas e processos próprios de aprendizagem. $\S 4^{\circ}$. O ensino fundamental será presencial, sendo o ensino a distância utilizado como complementação da aprendizagem ou em situações emergenciais (grifou-se).

A educação das crianças e adolescentes é um tema relevante inclusive para o Código Penal de 1940, haja vista que no artigo 246 prevê-se o crime de abandono intelectual, quando os pais, sem justificação deixam de garantir a instrução primária dos filhos em idade escolar. A pena é de detenção de quinze dias a um mês, ou estabelecimento de multa. Destarte, importante ressaltar que o crime pode se caracterizar pela falta de matrícula, o que leva a reduzir as possibilidades de uma desescolarização.

\footnotetext{
3،“Art. 208. O dever do Estado com a educação será efetivado mediante a garantia de: I - educação básica obrigatória e gratuita dos 4 (quatro) aos 17 (dezessete) anos de idade, assegurada inclusive sua oferta gratuita para todos os que a ela não tiveram acesso na idade própria $[\ldots] \S 1^{\circ} \mathbf{O}$ acesso ao ensino obrigatório $\mathbf{e}$ gratuito é direito público subjetivo [...] $\S 3^{\circ}$ Compete ao Poder Público recensear os educandos no ensino fundamental, fazer-lhes a chamada e zelar, junto aos pais ou responsáveis, pela freqüência à escola" (grifou-se).
} 
O Projeto de Lei ${ }^{\circ} 3.179$ de 08 de fevereiro de $2012^{4}$, de autoria do deputado Lincoln Portela, de Minas Gerais, propõe a modificação da LDBEN para que expressamente tenha-se a possibilidade de educação domiciliar no Brasil. Acrescenta parágrafo ao art. 23 da LDBEN, que oferta a educação realizada diretamente pela família ${ }^{5}$. Em 31 de janeiro de 2015 a proposta foi arquivada, e em 06 de fevereiro de 2015 foi desarquivada, e permanece na mesa diretora da Câmara Federal. Leve-se em conta que foi aprovada pela Comissão de Educação da Câmara dos Deputados em 11 de novembro de 2014, em relatoria da Deputada Dorinha Seabra Rezende.

Segundo o relatório, outras propostas anteriores foram rejeitadas, com a justificativa de que não se coadunavam com a obrigação dos pais de matricularem os filhos numa instituição de ensino. Argumentava-se contra, ainda, que a educação domiciliar poderia se caracterizar como uma "medida elitista", que mitigaria a socialização das crianças e adolescentes. A relatora refutou os argumentos, e ressaltou que a mudança proposta na LDBEN não significa a ausência completa das instituições de ensino na educação ou do Estado, porém, garante-se uma nova alternativa aos pais e filhos. Assim, explica a Dep. Dorinha Rezende:

Um dos méritos das proposições, portanto, é o de admitir, sem obrigar, a possibilidade de uma diferenciação na responsabilidade pela educação básica, autorizando os sistemas de ensino a prever, em suas normas, a alternativa de que pais e tutores se responsabilizem diretamente pela condução do processo ensino/aprendizagem de crianças e jovens de suas famílias. Ressalte-se novamente que o projeto principal especifica que deve haver diretrizes que assegurem a articulação, a supervisão e a avaliação periódica da aprendizagem pelos órgãos próprios dos sistemas de ensino. O projeto apensado, por seu turno, autoriza a educação domiciliar, nos termos da regulamentação do sistema de ensino, sendo obrigatória a matrícula e a obediência a calendário de avaliações (BRASI, Câmara dos Deputados, 2012, online).

\footnotetext{
${ }^{4}$ Antes dessa proposição legislativa houve os seguintes projetos de lei, similares, porém, rejeitados pelos parlamentares na Comissão de Educação e Cultura: PL no 6001/2001; PL no 6484/2002; PL nº 3518/2008; PL no $4122 / 2008$.

${ }^{5}$ Possível parágrafo proposto no Projeto de Lei no 3.179/2012: “§ $3^{\circ}$ É facultado aos sistemas de ensino admitir a educação básica domiciliar, sob a responsabilidade dos pais ou tutores responsáveis pelos estudantes, observadas a articulação, supervisão e avaliação periódica da aprendizagem pelos órgãos próprios desses sistemas, nos termos das diretrizes gerais estabelecidas pela União e das respectivas normas locais, que contemplarão especialmente: I - autorização pelo órgão competente do sistema de ensino; II - acompanhamento pelo órgão competente do trabalho dos pais ou responsáveis na condução do processo de ensino e aprendizagem; III obrigatoriedade de matrícula do estudante em escola pública; IV - manutenção de registro oficial das famílias optantes pela educação domiciliar; V - cumprimento de currículo mínimo e avaliação da aprendizagem, nos termos e na periodicidade estabelecidos no projeto pedagógico da escola em que o estudante estiver matriculado; VI - participação do estudante nos exames do sistema nacional e local de avaliação da educação básica; VII previsão de inspeção educacional, pelo órgão competente do sistema de ensino, no ambiente em que o estudante estiver recebendo a educação domiciliar".
} 
Afastar completamente a escola ou as diretrizes educacionais do Ministério da Educação (MEC) não é o intento da proposição legislativa. Tanto que deverão ser feitos exames periódicos e deverá existir vinculação a alguma instituição de ensino. O que se pretende é que haja a possibilidade dos pais optarem por uma relação de ensino e aprendizagem mais próxima à educação moral e famíliar. Contudo, deve-se cuidar para que a regulamentação, não acabe por engessar a liberdade dos pais, e se transforme a educação domiciliar numa extensão da escola, não o oposto.

Destarte, traz-se novamente a perspectiva de Édison Prado de Andrade (2014, p. 389), a defender que a função de educar é precipuamente da família. No Brasil, ainda é incipiente a educação domiciliar e a desescolarização. Contudo, há pessoas que a adotam, e em que pese o ordenamento vedar o abandono intelectual, ele é silente quanto à educação formal pela família. Regulamentar essa metodologia de educar não significa extirpar o ensino institucional ou mesmo retirar a atuação estatal, mas sim estabelecer regras claras e fiscalização com vistas ao melhor interesse e prioridade absoluta de crianças e adolescentes.

No que se refere às decisões judiciais no âmbito dos tribunais superiores, há o Mandado de Segurança $n^{\circ} 7.407$ de 24 de abril de 20026 : o Superior Tribunal de Justiça julgou improcedente o pedido de pais que solicitavam a possibilidade de educação domiciliar de seus filhos. Apesar do resultado contrário à liberdade da família quanto à escolha pela educação domiciliar, é oportuno observar os votos dos ministros, haja vista que não foi unânime a votação, pois houve votos vencidos e com algumas ponderações.

O relator do processo, Ministro Francisco Peçanha Martins decidiu por não reconhecer o direito aos pais de ensinarem os filhos em casa, independente da frequência escolar, e com ele votaram os Ministros: Humberto Gomes de Barros, Eliana Calmon, Francisco Falcão, Laurita Vaz e Garcia Vieira. Os votos vencidos foram os Ministros Ministros Franciulli Netto e Paulo Medina. Observa-se ainda que o instrumento do mandado de segurança realmente demonstra-se inadequado, haja vista a falta de previsão legal da educação domiciliar.

Os pais de três crianças impetraram o mandado de segurança no intuito de que fosse garantido o ensino em casa, independente da frequência escolar, mas com a matrícula em colégio regular e as devidas avaliações para comprovar a instrução dos filhos, com base na autonomia privada, inerente ao poder familiar e no direito de liberdade. A autoridade coatora acionada foi o Ministério da Educação que emitiu um parecer pela Câmara de Ensino Básico do Conselho Nacional de Educação (CEB/CNE) e denegou o pedido dos pais. 
O Ministro Francisco Peçanha Martins relator foi contrário ao pedido de direito líquido e certo dos impetrantes, pois não havia norma expressa que assegurasse a educação em domicílio. E, portanto, não competiria ao Judiciário, mas ao Legislativo assegurar tal possibilidade. Assim como entendeu que não ter havido ilegalidade ou abuso por parte do MEC, haja vista que a legislação prevê a necessidade de matrícula em rede regular de ensino, e se trata de uma obrigação dos pais, conforme a LDBEN e ECA.

Seguindo outra perspectiva, o Ministro Franciulli Netto compreendeu que a educação deve ser vista pela ótica do pluralismo do Estado Democrático de Direito, assim como o direito à liberdade -não só dos pais, mas da família- de optar por outra modalidade de ensino. Para o ministro, os pais estavam aptos para educação domiciliar, pois as crianças demonstraram uma capacidade avançada, haja vista que estavam um ano à frente às suas idades. Assim, a frequência escolar, segundo o juízo, é subsidiária. A educação vai além da mera transmissão de informações, sendo a família a responsável principal pela formação não só intelectual, mas cidadã e social das crianças e adolescentes, conforme o artigo 22 do ECA/90.

O Ministro Paulo Medina, também favorável à petição, ressaltou a liberdade prevista nos dispositivos constitucionais relativos à educação (artigo 205 a 208, CF/88) e a noção de pluralismo de ideias. E ainda ressalvou que a tarefa do Estado de zelar pela educação da criança e adolescente não restaria obstruída pelo ensino realizado diretamente pelos pais, uma vez que os resultados de exames oficiais demonstrariam o cumprimento do dever pelos genitores ou responsáveis. Assim afirma:

Cumprindo a família, de forma excelente, como comprovado no caso dos autos, a obrigação de prover à educação dos filhos, afasta-se a necessidade da interferência comissiva do Estado, que deve se limitar à fiscalização das atividades dessa entidade social, para garantia da efetivação dos fins constitucionalmente fixados, isto é, „pleno desenvolvimento da pessoa, seu preparo para o exercício da cidadania e sua qualificação para o trabalho" (BRASIL, STJ, 2002, p. 57).

\footnotetext{
6“MANDADO DE SEGURANÇA. ENSINO FUNDAMENTAL. CURRICULO MINISTRADO PELOS PAIS INDEPENDENTE DA FREQUÊNCIA À ESCOLA. IMPOSSIBILIDADE. AUSÊNCIA DE DIREITO LÍQUIDO E CERTO. ILEGALIDADE E/OU ABUSIVIDADE DO ATO IMPUGNADO. INOCORRÊNCIA. LEI 1.533/51, ART. $1^{\circ}$, CF, ARTS. 205 E 208, § 3º LEI 9.394/60, ART. 24, VI E LEI 8.096/90, ARTS. $5^{\circ}$, 53 E 129. 1. Direito líquido e certo é o expresso em lei, que se manifesta inconcusso e insuscetível de dúvidas. 2. Inexiste previsão constitucional e legal, como reconhecido pelos impetrantes, que autorizem os pais ministrarem aos filhos as disciplinas do ensino fundamental, no recesso do lar, sem controle do poder público mormente quanto à frequência no estabelecimento de ensino e ao total de horas letivas indispensáveis à aprovação do aluno. 3. Segurança denegada à míngua da existência de direito líquido e certo.”
} 
Em sede de outro julgado em tribunal superior, também relacionado ao ensino formal realizado no ambiente doméstico, em 04 de junho de 2015 foi publicada decisão do Supremo Tribunal Federal reconheceu a repercussão geral do Recurso Extraordinário $n^{\circ} 888.815$ do $\mathrm{RS}^{7}$. Segundo Ministro Luís Roberto Barroso, relator do caso, a repercussão foi aceita pela maioria dos ministros, sendo votos vencidos os Ministros Dias Toffoli e Teori Zavascki, e sem a manifestação das Ministras Rosa Weber e Cármen Lúcia. Os magistrados reputaram, também, a questão como constitucional, haja vista que observam-se os limites da educação domiciliar, e as relações entre Estado e família, no que concerne ao direito à educação.

No pedido do RE $n^{\circ} 888.815$ requer-se a reforma de decisão do Tribunal de Justiça do Rio de Grande do Sul, que diante da falta de previsão denegou mandado de segurança quanto à possibilidade de educação domiciliar, impetrado contra a Secretária Municipal de Educação de Canela/RS, que não aprovou pedido dos pais para educar os filhos em casa, e determinou a imediata matrícula na rede regular de ensino.

O Ministro Barroso destacou que o caso trata dos limites da liberdade dos pais de escolher a modalidade de educação dos filhos. Há uma controvérsia entre as obrigações da família e do Estado para com a efetivação e garantia da educação das crianças e adolescentes, os contornos da autonomia privada e intervenção estatal. Ele reconheceu o caráter constitucional e a repercussão do caso, pois a ANED expõe que o número de adeptos tem aumentado $^{8}$, há diversos países de índole democrática que adotam a educação realizada em casa pelos pais ou preceptores, e diante da previsão constitucional da educação.

A educação domiciliar demonstra-se um assunto de interesse geral. Não porque todas as famílias passaram a utilizar esta metodologia, mas porque há a possibilidade de escolha, e liberdade da família (pais e filhos) em optar pelo ensino no ambiente doméstico. Apesar da falta de regulamentação, o assunto está em discussão nos Poderes Legislativo e Judiciário. Embora a decisão do STJ não seja favorável, houve votos vencidos, que devem ser considerados, e a Repercussão Geral considerada pelo STF também é um indicativo de que a educação domiciliar precisa de um marco legal.

\footnotetext{
7“"DIREITO CONSTITUCIONAL. EDUCAÇÃO. ENSINO DOMICILIAR. LIBERDADES E DEVERES DO ESTADO E DA FAMÍLIA. PRESENÇA DE REPERCUSSÃO GERAL. 1. Constitui questão constitucional saber se o ensino domiciliar (homeschooling) pode ser proibido pelo Estado ou viabilizado como meio lícito de cumprimento, pela família, do dever de prover educação, tal como previsto no art. 205 da CRFB/1988. 2. Repercussão geral reconhecida" (BRASIL, STF, 2015, p. 1).
} 


\section{CONCLUSÃO}

A educação, no que se refere às crianças e adolescentes, está constitucionalmente expressa como um dever da família, da sociedade e do Estado. Portanto, incumbe aos três círculos garantir-lhes o direito à educação. Resta claro que a família, na figura dos pais ou responsáveis tem o dever precípuo de proporcionar a educação moral aos filhos ou pupilos. Por isso, ainda que estes frequentem regularmente uma escola, não podem os pais deixar de exercer o poder familiar, de modo a educá-los e orientá-los no processo de desenvolvimento de suas potencialidades e personalidade.

Não há no Brasil utilização massiva da educação domiciliar; porém, existem famílias que optaram por esta modalidade, e acabam por enfrentar alguns entraves jurídicos, diante da obrigação de matrícula e frequência escolar. Apesar disso, deve-se levar em conta que os pais que escolhem a educação domiciliar não estão desvinculando o Estado da educação dos filhos. Não se trata de um abandono intelectual, mas de uma forma alternativa de garantir a instrução científica e ética, que também pode ser realizada em casa, não apenas nas escolas, pois ensino/aprendizado e escola não são iguais, ainda que esta seja um ambiente que deva propiciar aquele.

Por conseguinte, observa-se que já existiram diversas proposições normativas e, até o final de 2015, resta em tramitação o PL no 3179/12, que prevê a regulamentação da educação domiciliar modificando a LDBEN, garantindo a possibilidade de que crianças e adolescentes sejam avaliados, e que órgãos estatais fiscalizem se os pais cumprem o dever de proporcionar a instrução aos filhos. A inserção da educação domiciliar como opção não significa a obsolescência do sistema escolar de educação formal. Importa, contudo, numa forma de garantir a liberdade e pluralidade de perspectivas de vida familiar no contexto do Estado.

Conclui-se que é possível a educação domiciliar, quando esta não for uma desvinculação completa dos particulares para com a sociedade e Estado. Haja vista que o direito à convivência comunitária é tão relevante quanto à convivência familiar, e os pais devem garanti-los. Afinal, a família é o primeiro ambiente de socialização, e a inserção da criança e do adolescente na vida comunitária é função dos pais, e não se realiza apenas pela escola regular. O Estado é um dos agentes colaboradores para efetivação dos direitos das

\footnotetext{
${ }^{8}$ Ilustra-se com uma reportagem da Folha de São Paulo, de 25 de fevereiro de 2015, que retrata a situação dos estudantes em educação domiciliar que prestam o Exame Nacional do Ensino Médio e obtém o certificado de conclusão do ensino médio (EX-ALUNOS..., 2015, online).
} 
crianças e adolescentes. Por fim, vê-se a necessidade de uma regulamentação que trate diretamente da educação realizada no espaço familiar, para que não se confunda com o abandono intelectual e não ocorram abusos por parte dos pais adeptos da educação em casa.

\section{REFERÊNCIAS}

ANDRADE, Édison Prado de. A educação familiar desescolarizada como um direito da criança e do adolescente: relevância, limites e possibilidades na ampliação do direito à educação. 2014, p. 552. Tese (Doutorado) - Faculdade de Educação da Universidade de São Paulo: São Paulo, 2014.

ASSOCIAÇÃO NACIONAL DE EDUCAÇÃO DOMICILIAR - ANED. O que é educação domiciliar? Disponível em: < http://www.aned.org.br/portal/index.php/ensino-domiciliar>. Acesso em: 01 dez. 2015.

BRASIL. Código Civil de 2002 (Lei no 10.406 de 10 de janeiro de 2002). Disponível em: < http://www.planalto.gov.br/ccivil_03/leis/2002/L10406.htm >. Acesso em: 01 dez. 2015.

BRASIL. Constituição da República Federativa do Brasil de 1988. Disponível em: <http://www.planalto.gov.br/ccivil_03/Constituicao/Constituicao.htm>. Acesso em: $01 \mathrm{dez}$. 2015 .

BRASIL. Convenção sobre os Direitos das Crianças de 20 de novembro de 1989 (Decreto n 99.710 de 21 de novembro de 1990). Disponível em:

<http://www.planalto.gov.br/ccivil_03/decreto/1990-1994/D99710.htm>. Acesso em: 31 jan. 2016.

BRASIL. Convenção sobre os Direitos das Crianças de 20 de novembro de 1989 (Decreto n 99.710 de 21 de novembro de 1990). Disponível em:

<http://www.planalto.gov.br/ccivil_03/decreto/1990-1994/D99710.htm>. Acesso em: 31 jan. 2016.

BRASIL. Estatuto da Criança e do Adolescente (Lei no 8.069 de 13 de julho de 1990). Disponível em: < http://www.planalto.gov.br/ccivil_03/LEIS/L8069.htm >. Acesso em: 01 dez. 2015.

BRASIL. Lei de Diretrizes e Bases da Educação Nacional (Lei no 9.394 de 20 de dezembro de 1996.). Disponível em: < http://portal.mec.gov.br/arquivos/pdf/ldb.pdf>. Acesso em: 01 dez. 2015.

BRASIL. Lei de Diretrizes e Bases da Educação Nacional (Lei no 9.394 de 20 de dezembro de 1996.). Disponível em: < http://portal.mec.gov.br/arquivos/pdf/ldb.pdf>. Acesso em: 01 dez. 2015. 
BRASIL. Lei no 12.010, de 3 de agosto de 2009 (Nova Lei de Adoção). Disponível em: < http://www.planalto.gov.br/ccivil_03/_ato2007-2010/2009/lei/112010.htm>. Acesso em: 05 fev. 2016.

BRASIL. Ministério da Educação - MEC. Diretrizes Curriculares Nacionais Gerais da Educação Básica. Brasília: MEC, SEB, DICEI, 2013.

BRASIL. Ministério da educação (MEC). Disponível em: < http://portal.mec.gov.br/>. Acesso em: 20 dez. 2015.

BRASIL. Ministério da educação (MEC). Planejando a próxima década: conhecendo as 20 metas do plano nacional de educação. Brasília: Ministério da Educação/Secretaria de Articulação com os Sistemas de Ensino (MEC/SASE), 2014.

BRASIL. SUPERIOR TRIBUNAL DE JUSTIÇA - STJ. Mandado de Segurança no 7.407 de 24 de abril de 2002. Disponível em:

<https://ww2.stj.jus.br/processo/revista/inteiroteor/?num_registro=200100228437\&dt_publica cao=21/03/2005>. Acesso em: 01 dez. 2015.

BRASIL. SUPREMO TRIBUNAL FEDERAL - STF. Repercussão Geral no Recurso Extraordinário no 888.815 do Rio Grande do Sul, 04 jun. 2015. Disponível em: $<$ http://redir.stf.jus.br/paginadorpub/paginador.jsp?docTP=TP\&docID=8678529>. Acesso em: 03 dez. 2015.

CURY, Carlos Roberto Jamil. A educação básica como direito. Cadernos de pesquisa, São Luís, v. 38, n. 134, p. 293-303, maio/ago., 2008.

EX-ALUNOS CONTAM EXPERIÊNCIA DE ENSINO DOMILIAR QUE CRESCE NO PAIS. Folha de São Paulo, 25 de fevereiro de 2015. Disponível em: < http://www1.folha.uol.com.br/equilibrioesaude/2015/02/1594329-ex-alunos-contamexperiencia-de-ensino-domiciliar-que-cresce-no-pais.shtml>. Acesso em: 06 dez. 2015.

INSTITUTO NACIONAL DE ESTUDOS E PESQUISAS EDUCACIONAIS ANÍSIO TEIXEIRA - INEP. Conheça o Inep, 2011. Disponível em:

<http://portal.inep.gov.br/conheca-o-inep>. Acesso em: 05 fev. 2016.

INSTITUTO NACIONAL DE ESTUDOS E PESQUISAS EDUCACIONAIS ANÍSIO TEIXEIRA - INEP. Programme for International Student Assessment - PISA. O que é o Pisa? Disponível em: < http://portal.inep.gov.br/pisa-programa-internacional-de-avaliacaode-alunos>. Acesso em: 05 fev. 2016.

MIRANDA, Pontes de. Tratado de direito da família. Campinas: Bookseller, 2001. ORGANIZAÇÃO DAS NAÇÕES UNIDAS - ONU. Declaração Universal dos Direitos Humanos de 10 de dezembro de 1948. Disponível em: <http://www.dudh.org.br/wpcontent/uploads/2014/12/dudh.pdf>. Acesso em: 31 jan. 2016. 
ORGANIZAÇÃO DAS NAÇÕES UNIDAS - ONU. Declaração Universal dos Direitos Humanos de 10 de dezembro de 1948. Disponível em: <http://www.dudh.org.br/wpcontent/uploads/2014/12/dudh.pdf $>$. Acesso em: 31 jan. 2016.

PEREIRA JÚNIOR, Antonio Jorge. A família na Constituição do Brasil - missão, limites e responsabilidades - comentário ao art. $226^{\circ}$ da Constituição de 1988. In: PEREIRA JÚNIOR, Antonio Jorge; GOZZO, Débora; LIGIERA, Wilson Ricardo (Org.). Direito e dignidade da família. São Paulo: Almedina, 2012. p. 7-45.

PEREIRA JUNIOR, Antonio Jorge. Privacidade no gerenciamento do poder familiar. In: MARTINS, Ives Gandra da Silva; PEREIRA JUNIOR, Antonio Jorge (Coord.). Direito à privacidade. São Paulo: Ideias e Letras, 2005. p. 149-211.

POMPEU, Gina Vidal Marcílio. Direito à educação: controle social e exigibilidade judicial. Rio de Janeiro; São Paulo: ABC, 2005.

SÃO JOSÉ, Fernanda Moraes de. O homeschooling sob a ótica do melhor interesse da criança e do adolescente. Belo Horizonte: Del Rey, 2014.

VASCONCELOS, Maria Celi Chaves; MORGADO, José Carlos Bernardino Carvalho. Desafios à escolarização obrigatória: a inserção do homeschooling na legislação educacional no Brasil e em Portugal. RBPAE, Goiânia, v. 30, n. 1, p. 203-230, jan./abr. 2014. 